\title{
Up-to-date Treatments of Primary Hyperhidrosis with Focus on Sympathectomy and Sympathicotomy; a Narrative Review
}

\author{
Shahram Manoochehry ${ }^{1, *}$, Hassan Ali Mohebi ${ }^{1}$, Mohammad Javad Behzadnia ${ }^{2}$, Reza Mohtashami ${ }^{2}$ \\ ${ }^{1}$ Department of General Surgery, Faculty of Medicine, Baqiyatallah University of Medical Sciences, Tehran, Iran \\ ${ }^{2}$ Department of Emergency Medicine, Faculty of Medicine, Baqiyatallah University of Medical Sciences, Tehran, Iran
}

*Corresponding Author: Shahram Manoochehry, MD, Department of General Surgery, Faculty of Medicine, Baqiyatallah University of Medical Sciences, Tehran, Iran. Tel: +98-21-81263516, Fax: +98-21-81263550, Email: shahram.manoochehry@yahoo.com

Received: 20 Aug. 2015; Accepted: 5 Oct. 2015; Online Publish: 11 Jan. 2016

\begin{abstract}
Background: Primary hyperhidrosis $(\mathrm{PH})$ refers to excessive sweating, beyond normal physiological levels, in specific sites of the body for unknown reasons. It is usually bilateral and is most prominent in the palms, axillae, feet, and face. PH prevalence is estimated to be $0 \%-6.1 \%$ in different populations. It usually begins in childhood and is more frequent in women. In $57 \%$ of cases, there is a positive family history. It is an autosomal dominant disorder with variable penetration in chromosomes 5,14 , or both.

Objective: The aim of this study was to illustrate current treatments of PH while focusing on surgical therapies through a narrative review.

Methods: A complete search of online articles from 2007 to 2014 in PubMed, Scopus, and the Cochrane Library was performed. A free search and a search in the MeSH database for the study's keywords were also done. More than 600 relevant articles were found, of which 51 were chosen for this study. This article is based on those articles.

Results: Surgery is the best and more permanent therapy for PH. The most common consequences of surgery are compensatory sweating and gustatory sweating. There is controversy concerning whether lowering the level and limiting the number of ganglia on which surgery is performed reduces compensatory sweating.

Conclusion: It seems that ramicotomy (selective division of the sympathetic postganglionic fibers) reduces compensatory sweating, but this theory should be confirmed with more studies.
\end{abstract}

Keywords: Hyperhidrosis, Sweating, Sympathectomy, Therapy, Operations

\section{Background}

The sweat glands are stimulated by numerous stimuli such as heat, physical activity, fever, and emotions, all of which are regulated by the neurovegetative system with the main role of the sympathetic nervous system in regulation of sweat glands. Primary hyperhidrosis $(\mathrm{PH})$ refers to a condition where, for unknown reasons, sweat secretions exceed normal physiological levels in specific areas of the body with unknown etiology [1]. It should be differentiated from secondary hyperhidrosis. PH is diagnosed when no known etiology for excessive sweating is found and diagnostic criteria for PH are met; secondary hyperhidrosis is hyperhydration caused by drugs or medical conditions (including endocrine, neurologic, cardiovascular, infectious, and neoplastic diseases). The prevalence of $\mathrm{PH}$ is estimated to range $0 \%-6.1 \%$ in different populations and is 20 times higher among Japanese people than Caucasians [2]. It usually begins in childhood and is more frequent in women. In $57 \%$ of cases, there is a positive family history [3]. Some articles have reported that $\mathrm{PH}$ is an autosomal dominant disorder with variable penetration in chromosomes 5 or 14 or both; in some cases congenital factors are involved $[4,5]$.

$\mathrm{PH}$ is usually bilateral and is most prominent in palms, axillae, feet, and the face. Its diagnosis is established upon excessive local sweating without a known cause for more than 6 months in conjunction with at least two of the following criteria: bilateral and rather symmetrical hyperhidrosis, frequency of at least one episode a week, impairment of daily activities, onset before the age of 25 years, a positive family history, and cessation of excessive sweating during sleep [6]. PH causes psychological problems for patients mostly through wet hands at work and in other social relationships [7]. Medical treatments such as topical agents, anti-anxiety drugs, antidepressants, oral anticholinergics, iontophresis, or botox injections are not sufficiently effective, and the response to treatment is usually transient. Surgical therapy is generally more effective, nearly permanent, and gives more satisfaction. It interrupts the transmission of sympathetic impulses from the sympathetic chain to the eccrine sweat glands. Hughs described thoracoscopic sympathectomy for the first time in 1942 , and since the 1980 s, this procedure has been the preferred therapeutic option for $\mathrm{PH}$. The most common side effects of this surgical procedure are CS, followed by GS. Other complications include Horner's syndrome (myosis, ptosis, anhidrosis) and pompholyx or dyshidrotic eczema (a palmar eczema characterized by maculopapular and vesicular rashes caused by severe palmar anhidrosis and dry skin) $[8,9]$.

Secondary hyperhidrosis is excessive perspiring secondary to an underlying disease and is related to different pathologies such as hyperthyroidism, phaeochromocytomas, carcinoid tumors, heart diseases, obesity, autonomous nervous system diseases and lesions, brain tumors, peripheral vascular diseases (Raynaud's syndrome, erythromelalgia, acrocyanosis, etc.), spinal cord diseases, and menopause [10]. 


\section{Objective}

This study was designed to illustrate the current treatments of primary hyperhidrosis, focusing on surgical therapies and their benefits, outcomes, and complications through a narrative review.

\section{Methods}

Complete searches were performed for online articles from 2007 to 2014 in PubMed (Medline database), Scopus, and the Cochrane Library. A free search was also made for the words "sympathectomy," "sympathicotomy," "primary hyperhidrosis," "compensatory sweating," "compensatory hyperhidrosis," and "reflex sweating." Moreover, the MeSH database was searched for keywords "hyperhidrosis/sympathectomy/sweating/therapy/operation

". More than 600 relevant articles were found. The most pertinent articles (a total of 50) that dealt with the subject of "PH and its treatments," especially surgical treatments and their outcomes and complications (such as CS), were chosen, and data from them was used in this review.

\section{Results}

\subsection{Medical Treatment}

As $\mathrm{PH}$ has an unknown etiology, the following symptomatic treatments are used [11]:

Hygiene protocols: Patients are recommended to use absorbent powders, cotton or woolen gloves, socks and clothing, leather shoes, avoiding plastic, rubber and artificial materials, etc.

Topical agents: These are rather effective at the beginning of therapeutic measures. For example, aluminum salts are effective in $12 \%-64 \%$ of cases, glutaraldehyde in about $10 \%$, tannic acid in $2 \%-5 \%$, and potassium permanganate reduces sweating in about $25 \%$ of patients. Complications from the use of topical agents are occlusion and atrophy of the sweat glands, skin irritation, the brown discoloration of the skin, irritation and the rebound effect. The effectiveness of the treatment decreases with continuing therapy [10].

Systemic anticholinergics (such as oxybutynin): Their efficacy is temporary. Furthermore, they have multiple side effects, including blurred vision, dryness of eyes, mouth and vagina, constipation, and urinary retention. These side effects limit their usage [12].

Iontophoresis: This is the electrocoagulation of sweat glands by applying 15-30 mA of electric current through ionized water solution 2- 3 times weekly with each session lasting 20-30 minutes. Anticholinergic drugs such as glycopyrronium bromide or poldine methylsulphate may be added to the water. Patients must continue the sessions to sustain the therapeutic effect; however, it is tiring and they usually abandon it [11].

Botox injections: Botulinum neurotoxin A temporarily improves hyperhidrosis. The hyperhidrosis zone is intradermally injected at multiple points $(1-2 \mathrm{~cm}$ apart). The injections should be repeated every 4-9 months. They may reduce the force of the underlying muscles [11].

Microwave thermolysis: This procedure treats hyperhidrosis by heating the distance between the skin and the subdermal fat and destroying sweat glands by means of microwave devices. It is mostly applicable for axillary hyperhidrosis. It reduces perspiration by about $50 \%-80 \%$ in $60 \%-90 \%$ of patients. One to three therapeutic sessions are usually required. The side effects of this procedure are swelling, discomfort, and numbness of the skin [13-15].
There is not sufficient evidence to support this therapeutic method, and long-term follow-up studies are needed.

Laser: It has not been proven that the topical use of laser to treat hyperhidrosis is efficient, and there is controversy about its effectiveness on hyperhidrosis in the literature [16, 17].

All medical treatments for PH have temporary effects and have different side effects which limit their usage by patients. Thus, patients seek treatments that will provide them with more permanence and fewer side effects. The answer is sympathectomy or sympathicotomy [11].

\subsection{Thoracic Sympathectomy or Sympathicotomy}

In patients with palmar, axillary, plantar or facial $\mathrm{PH}$, either sympathectomy or sympathicotomy is used as a permanent remedy [7].

\subsection{Candidates for Surgery}

Most patients undergo surgery when they are 20-30 years old. Although there are reports of surgery for $\mathrm{PH}$ in children with good results, the proper age range for $\mathrm{PH}$ surgery is from 18 to 40 years old. Doctors should be more careful in choosing pre- and post-menopausal women and undeveloped teenagers for surgery [18-20]. Patients who experienced the onset of PH below the age of 16 years, whose current age range is 18-25, who are relatively healthy with a body mass index below $28 \mathrm{Kg} / \mathrm{m} 2$, and who do not have bradycardia (resting heart rate $>55$ beats per minute) are ideal candidates for thoracoscopic sympathetic surgery [20].

\subsection{Details of the Procedure and Functional Anatomy}

Patients of $\mathrm{PH}$ usually undergo a one-stage bilateral thoracoscopic surgery [1]. Although most are performed under general anesthesia with selective or common tracheal intubation, some use simple tracheal intubation for lung collapse and better exposure use $\mathrm{CO} 2$ insufflation. Local anesthesia may also be used for these surgeries $[1,9,10$, 19]. The most common patient position during surgery is semi-sitting or sitting with $90^{\circ}$ abduction of the upper extremities (semi-Fowler position). For a sympathicotomy, usually a single 8 or $10 \mathrm{~mm}$ trocar is inserted through the third intercostal space in the mid- to anterior axillary line so that a thoracoscope with a working channel may be used; if a simple thoracoscope is used, an additional $5 \mathrm{~mm}$ trocar is needed $[1,19,20]$. For a sympathectomy, a second trocar and with a simple thoracoscope a third trocar may be used. During thoracoscopy, the uppermost intercostal muscle and rib (which are seen in the posterolateral of the surgery field) are the first intercostal muscle and the second rib. The sympathetic chain usually lies posterior to the parietal pleura on the heads of the ribs. Each named thoracic sympathetic ganglion is usually located on the same intercostal space. The sympathetic ganglia dermatomes overlap each other, but it appears that the T2 ganglion is mostly engaged in innervation of the head, neck, and upper extremity. The T3 ganglion is engaged in the innervation of the upper extremity and upper third of the axillary fossa, and the T4 ganglion is engaged in innervation of the upper extremity and lower third of the axillary fossa $[9,10,20$, 21].

During a sympathectomy the corresponding ganglia are removed, although in a sympathicotomy (sympathotomy) the sympathetic chain is transected on the upper portion of the rib just below the intercostal space where the ganglion lies. Recently, it has become more accepted to disconnect 
the sympathetic chain (sympathicotomy) at appropriate levels $[6,21,22]$. The new nomination system uses the number of ribs upon which the sympathetic chain is cut (R) instead of the number of sympathetic ganglion (T) $[1,6$, 22]. These manipulations on the sympathetic chain are carried out via different devices and techniques, such as electrocautery (monopolar or bipolar), the Harmonic scalpel, radiofrequency, and clamping [23-26]. To increase the surgical success rate and decrease recurrence, any accessory nerve tract to other ganglions and to intercostal nerves (Kuntz's fibers) must be disconnected [27].

Thoracostomy tube placement may be performed but is not necessary. Some surgeons use a draining tube connected to a sealing system to evacuate the pneumothorax. When there is no lung injury, pneumothorax, or plural effusion, the draining tube is removed sometime after surgery [10], although many others insert a small catheter at the end of the operation and remove it by performing a valsalva maneuver [19].

Some studies have reported achieving access transumbilically and then through the diaphragm for thoracoscopy and thoracic sympathectomy. They suggest that the transumbilical approach reduces post-operative pain and paraesthesia [28, 29].

\subsection{Surgery Outcomes and Consequences}

Satisfaction and cure rates after surgery are reported to be 91.3\%-100\% in most cases of palmar hyperhidrosis, but some reports from East Asia have proclaimed rates of 72\%$79 \%$ (Table 1). Satisfaction and cure rates after surgery for axillary hyperhidrosis are reported to be $72.2 \%-93 \%$, followed by $43 \%-60 \%$ for plantar and craniofacial hyperhidrosis. Failure rates in technique are reported to be $0 \%-2 \%$ for sympathectomy and $3.4 \%-5 \%$ for sympathetic clipping [3, 9, 10, 17, 21, 24].

Thoracic sympathetic chain interruption affects cardiac and respiratory function by increasing efferent cardiac vagal activity and baroreceptor sensitivity, causing mild bradycardia, and decreasing ejection fraction. Respiratory effects include a mild increase in airway resistance, a small reduction in forced (maximum) expiratory volume in 1 second (FEV1), and an insignificant reduction in carbon monoxide diffusion capacity (DLCO). None of the cardiac or respiratory effects are clinically important $[30,31]$.

The rate of recurrence for $\mathrm{PH}$ after successful anhidrosis treatment is reported to be $0 \%-2 \%$. It is more prevalent in axillary hyperhidrosis, but can be successfully treated with reoperation $[1,7,9,20,21,32,33]$. Some authors believe that the recurrence of $\mathrm{PH}$ after surgery is related to ignorance in cutting the previously called Kuntz fibers [21]. All recent studies report no mortality and morbidity of around $4 \%-5 \%$. The most common consequence is compensatory sweating, which is excessive sweating in the back, abdomen, anterior thorax, buttocks, and thighs. It is not relevant to stress or anxiety as in essential or primary hyperhidrosis, but it is related to physical activity and environmental temperature. CS is generally reported in 28$100 \%$ of cases during the early post-operation period, but 2 to 3 years after surgery its occurrence rate is reduced to $21 \%-47 \%$. Although CS has a rather high prevalence, it is severe in only $0-14 \%$ of patients during the early postoperation period, and its severity declines with time (Table 1) $[1,7,21,26,29,33-38]$.

Another consequence of surgery may be gustatory sweating (GS), which is excessive sweating during eating and chewing, mostly in the head and neck. GS prevalence in the early post-operation period is reported to be $5 \%-50 \%$, but it is nearly always mild, and its prevalence declines with time to $1 \%-5 \%[1,7,21]$.

\subsection{Complications of Surgery}

The most common complication of surgery is pneumothorax, which is reported in $0 \%-3 \%$ of cases. These cases are usually mild, however, and in most, only $20 \%$ $40 \%$ of pneumothoraces need a thoracostomy tube. Subcutaneous emphysema is reported in up to $1 \%$ of cases, and plural effusion and hemothorax in $0 \%-0.5 \%$. Some rare complications, such as intercostal vessel injury, chylothorax, brachial plexus nerve injury, lung puncture, or sudden cardiac arrest, are reported in the literature $[1,7,20$, 21, 33].

Surgical site pain and neuralgia differ depending on how the thoracoscopy is performed (single port, double port, or transumbilically). No paper was found that compared the transumbilical approach with transthoracic thoracoscopic surgery [1, 7, 21, 28, 29].

Complications such as ptosis and Horner's syndrome usually occur in less than $1 \%$ of patients. Pompholyx (dyshidrotic eczema) also occurs about $1 \%$ of the time, but in some series this rate was reported to be as high as $10 \%$ $20 \%$ in the early post-operation period. About 1 year after surgery, it declines to $3 \%-13 \%$; its severity was reported as being so mild that patient satisfaction was not affected [1, $7,20,21,33,39]$.

Table 1. Compensatory sweating according to the type and technique of sympathetic surgery

\begin{tabular}{|c|c|c|c|c|c|c|c|c|c|}
\hline Author & $\begin{array}{c}\text { Year of } \\
\text { Publication }\end{array}$ & Type of Study & $\begin{array}{c}\text { No. of } \\
\text { Patients }\end{array}$ & $\begin{array}{c}\text { Mean } \\
\text { Age }\end{array}$ & $\begin{array}{l}\text { Level of } \\
\text { Surgery }\end{array}$ & Type of Surgery & $\begin{array}{c}\text { Rate of } \\
\text { C.S }\end{array}$ & $\begin{array}{c}\text { Rate of C.S. } \\
\text { Severity }\end{array}$ & $\begin{array}{c}\text { Satisfaction } \\
\text { and Cure Rate }\end{array}$ \\
\hline Yanagihara [26] & 2010 & Retrospective & 84 & ---- & R3 & Sympathectomy & $62 \%$ & $4 \%$ & $95 \%$ \\
\hline IShy [34] & 2011 & Prospective & 20 & 25.1 & R3 & Sympathectomy & $70 \%$ & $5 \%$ & $100 \%$ \\
\hline IShy [34] & 2011 & Prospective & 20 & 25 & R4 & Sympathectomy & $75 \%$ & $5 \%$ & $100 \%$ \\
\hline de Lima [33] & 2011 & Prospective & 75 & ---- & R3-R4 & Sympathecotomy & $67 \%$ & $6.9 \%$ & $100 \%$ \\
\hline Atkinson [35] & 2011 & Retrospective & 155 & ---- & R1-R2 & Sympathicotomy & $68.3 \%$ & $1.3 \%$ & $96.6 \%$ \\
\hline Flores [24] & 2012 & Prospective & 36 & 25.3 & R2-R3-R4 & Sympathicotomy & $86 \%$ & $6.2 \%$ & $100 \%$ \\
\hline Mohebbi [21] & 2012 & Prospective & 30 & 23.6 & R2-R3-R4 & Sympathecotomy & $90 \%$ & $3.3 \%$ & $98 \%$ \\
\hline Mohebbi [21] & 2012 & Prospective & 30 & 24.7 & R2-R3-R4 & Sympathicotomy & $73.3 \%$ & $0 \%$ & $99 \%$ \\
\hline Hwang [36] & 2013 & Prospective & 46 & 23.6 & R3 & Sympathicotomy & $80.4 \%$ & $8.7 \%$ & $91.3 \%$ \\
\hline Hwang [36] & 2013 & Prospective & 43 & 24.7 & R3-R4 & Sympathicotomy & $95.3 \%$ & $14 \%$ & $79.1 \%$ \\
\hline Yuncu [37] & 2013 & Prospective & 17 & 25.52 & R3-R4 & Sympathicotomy & $100 \%$ & $0 \%$ & $100 \%$ \\
\hline Yuncu [37] & 2013 & Prospective & 43 & 24.09 & R3 & Sympathicotomy & $79 \%$ & $0 \%$ & $100 \%$ \\
\hline Coveliers [38] & 2013 & Retrospective & 55 & 28 & R2-R3-R4 & Ramicotomy & $7.2 \%$ & $0 \%$ & $96 \%$ \\
\hline ZHU [29] & 2014 & Prospective & 17 & 21.2 & R3 & Sympathicotomy & 28.6 & $0 \%$ & $97.1 \%$ \\
\hline ZHU [29] & 2014 & Prospective & 18 & 21.2 & R3-R4 & Sympathicotomy & $48 \%$ & $5.55 \%$ & $72.2 \%$ \\
\hline Mohebbi [39] & 2014 & Prospective & 47 & 26.3 & R3-R4 & Sympathicotomy & $78.7 \%$ & $0 \%$ & $98.6 \%$ \\
\hline Mohebbi [39] & 2014 & Prospective & 47 & 26.6 & R4-R5 & Sympathicotomy & $65.9 \%$ & $6.3 \%$ & $97.3 \%$ \\
\hline
\end{tabular}




\section{Discussion}

Thoracoscopic sympathectomy or sympaticotomy is the principal treatment for patients with severe hyperhidrosis. There is some controversy over which surgical approach gives better results and fewer complications like CS.

Some studies achieved a lower rate of CS when surgery was carried out on the lower ganglia; however, other studies have reported no decline in CS when the level of sympathetic surgery is lowered. These papers have also reported lower occurrence rates for other complications, such as pneumothorax pompholyx and gustatory sweating [8, 22, 34, 39]. According to the majority of studies, performing surgery on fewer ganglia does not decrease CS, but operating on a single ganglion does. Some studies, however, have reported no reduction in CS in surgeries on even a single ganglion [40-42].

A very low prevalence of post-operative CS (7.2\%) is reported in a case series of selective postganglionic thoracic sympathicotomy (or ramicotomy) performed via robotic VATS surgery. With this technique, selective division of the sympathetic postganglionic fibers (ramicotomy) that supply the eccrine glands of the upper extremity (not the interganglionic fibers) was performed. It seems that more surgeries should be conducted using this method to confirm that it is sufficiently efficient and has a low rate of CS [38].

Some studies have reported a decrease in the severity of CS with the passage of time. This may be because the patients grow accustomed to CS, although other studies have reported that $\mathrm{CS}$ is reduced in some patients while remaining stable in others with the passage of time [7, 21, 39].

There are different therapeutic options for CS (as for PH itself), such as topical aluminum salts, antianxieties, anti-depressants, oral anti-cholinergics, botox injections, and sympathetic nerve reconstruction with nerve or vein grafts [43, 44]. Two studies reported cases where CS occurred after the sympathetic chains were clamped, and clips were removed as treatment for severe CS. In 48\%-68\% of these cases, CS was improved. However, the low number of unclipping cases reported in these studies (15 and 34 cases, respectively) and their short followup time, studies with more patients and a longer follow-up period are needed to determine if clipping is a reversible method and if unclipping will improve CS. Moreover, the upper limit of unclipping time should be defined, because Thomsen et al. reported severe histologic nerve damage visible 4 weeks after unclipping of the sympathetic chain in sheep, in which the damage decreased markedly 12 weeks after unclipping. Clips were removed 7 days after they were applied [45-48]. Studies on animals with unclipping times ranging from a few months to over 1 year after clipping are also necessary to evaluate nerve histology and the reversibility of their function after this period.

To evaluate surgical results and the severity of the resultant CS, Miller et al. [49] suggest that a temporary anesthetic block of sympathetic ganglia with Bupivacaine be applied before surgery. If patients are satisfied with the result and can tolerate the CS, then definitive surgery can be carried out. Even though this procedure has its particular problems, it may be a good way to evaluate the severity of the resultant CS before the definitive surgery is performed [50].

\section{Conclusion}

Medical therapies are not effective enough to treat $\mathrm{PH}$; response is usually transient, and patient satisfaction rates are low. Thoracoscopic interruption of the sympathetic chain is usually more effective, is nearly permanent, and results in greater satisfaction with an acceptable severity of CS.

The prevalence of CS is reported very differently in different studies. The reason is not quite clear, but it may be related to the levels and numbers of sympathetic chain interruptions. Controversy still exists concerning whether lowering the level and limiting the number of ganglia in operations will reduce CS. Another important reason may be ethnic differences, as it seems that the rates of CS reported in studies performed in identical ethnical backgrounds are closer.

Ramicotomy is suggested to reduce CS, but more trials are needed to confirm this theory.

\section{Acknowledgments}

We would like to thank from the "Clinical Research Development Unit" of Baqiyatallah Hospital for their kindly cooperation.

\section{Authors' Contributions}

Study design and concept: SM, Acquisition of data: MJB, Analysis and data interoperation: SM and HAM, Drafting of the manuscript: SM and RM. Revision of the manuscript for important intellectual content: HAM, SM and RM, Administrative, material and technical support: SM and RM.

\section{Conflict of Interest}

Authors declare that they have no conflict of interest.

\section{References}

1. Cerfolio RJ, De Campos JR, Bryant AS, Connery CP, Miller DL, DeCamp MM, et al. The Society of Thoracic Surgeons expert consensus for the surgical treatment of hyperhidrosis. Ann Thorac Surg. 2011;91(5):1642-8. [DOI]

2. Yamashita N, Tamada Y, Kawada M, Mizutani K, Watanabe D, Matsumoto Y. Analysis of family history of palmoplantar hyperhidrosis in Japan. J Dermatol. 2009;36(12):628-31. [DOI]

3. Bechara FG, Gambichler T, Bader A, Sand M, Altmeyer P, Hoffmann K. Assessment of quality of life in patients with primary axillary hyperhidrosis before and after suction-curettage. J Am Acad Dermatol. 2007;57(2):207-12. [DOI]

4. Ro KM, Cantor RM, Lange KL, Ahn SS. Palmar hyperhidrosis: evidence of genetic transmission. J Vasc Surg. 2002;35(2):382-6. [DOI]

5. Higashimoto I, Yoshiura K, Hirakawa N, Higashimoto K, Soejima $\mathrm{H}$, Totoki $\mathrm{T}$, et al. Primary palmar hyperhidrosis locus maps to 14q11.2-q13. Am J Med Genet A. 2006;140(6):567-72. [DOI]

6. Kuijpers M, Klinkenberg TJ, Bouma W, DeJongste MJ, Mariani MA. Single-port one-stage bilateral thoracoscopic sympathicotomy for severe hyperhidrosis: prospective analysis of a standardized approach. J Cardiothorac Surg. 2013;8:216. [DOI]

7. Lyra Rde M, Campos JR, Kang DW, Loureiro Mde P, Furian MB, Costa MG, et al. Guidelines for the prevention, diagnosis and treatment of compensatory hyperhidrosis. J Bras Pneumol. 2008;34(11):967-77.

8. Scognamillo F, Serventi F, Attene F, Torre C, Paliogiannis P, Pala C, et al. T2-T4 sympathectomy versus T3-T4 sympathicotomy for palmar and axillary hyperhidrosis. Clin Auton Res. 2011;21(2):97102. [DOI]

9. Rodriguez PM, Freixinet JL, Hussein M, Valencia JM, Gil RM, Herrero J, et al. Side effects, complications and outcome of thoracoscopic sympathectomy for palmar and axillary hyperhidrosis in 406 patients. Eur J Cardiothorac Surg. 2008;34(3):514-9. [DOI]

10. Macia I, Moya J, Ramos R, Rivas F, Urena A, Rosado G, et al. [Primary hyperhidrosis. Current status of surgical treatment]. Cir Esp. 2010;88(3):146-51. [DOI] 
11. Flanagan $\mathrm{KH}$, King R, Glaser DA. Botulinum toxin type a versus topical $20 \%$ aluminum chloride for the treatment of moderate to severe primary focal axillary hyperhidrosis. J Drugs Dermatol. 2008;7(3):221-7.

12. Wolosker N, Campos JR, Kauffman P, Munia MA, Neves S, Jatene $\mathrm{FB}$, et al. The use of oxybutynin for treating facial hyperhidrosis. An Bras Dermatol. 2011;86(3):451-6. [DOI]

13. Johnson JE, O'Shaughnessy KF, Kim S. Microwave thermolysis of sweat glands. . Lasers Surg Med. 2012;44(1):20-5. [DOI]

14. Glaser DA, Coleman WP, 3rd, Fan LK, Kaminer MS, Kilmer SL, Nossa R, et al. A randomized, blinded clinical evaluation of a novel microwave device for treating axillary hyperhidrosis: the dermatologic reduction in underarm perspiration study. Dermatol Surg. 2012;38(2):185-91. [DOI]

15. Hong HC, Lupin M, O'Shaughnessy KF. Clinical evaluation of a microwave device for treating axillary hyperhidrosis. Dermatol Surg. 2012;38(5):728-35. [DOI]

16. Bechara FG, Georgas D, Sand M, Stucker M, Othlinghaus N, Altmeyer $\mathrm{P}$, et al. Effects of a long-pulsed 800-nm diode laser on axillary hyperhidrosis: a randomized controlled half-side comparison study. Dermatol Surg. 2012;38(5):736-40. [DOI]

17. Letada PR, Landers JT, Uebelhoer NS, Shumaker PR. Treatment of focal axillary hyperhidrosis using a long-pulsed Nd:YAG $1064 \mathrm{~nm}$ laser at hair reduction settings. J Drugs Dermatol. 2012;11(1):59-63.

18. Neves S, Uchoa PC, Wolosker N, Munia MA, Kauffman P, de Campos JR, et al. Long-term comparison of video-assisted thoracic sympathectomy and clinical observation for the treatment of palmar hyperhidrosis in children younger than 14. Pediatr Dermatol. 2012;29(5):575-9. [DOI]

19. Steiner Z, Cohen Z, Kleiner O, Matar I, Mogilner J. Do children tolerate thoracoscopic sympathectomy better than adults? Pediatr Surg Int. 2008;24(3):343-7. [DOI]

20. Krasna MJ. The role of surgical treatment of hyperhidrosis. Mayo Clin Proc. 2011;86(8):717-8. [DOI]

21. Mohebbi HA, Mehrvarz S, Manoochehry S. Thoracoscopic Sympathicotomy vs Sympathectomy in Primary Hyperhidrosis. Trauma Mon. 2012;17(2):291-5. [DOI]

22. Liu Y, Yang J, Liu J, Yang F, Jiang G, Li J, et al. Surgical treatment of primary palmar hyperhidrosis: a prospective randomized study comparing T3 and T4 sympathicotomy. Eur J Cardiothorac Surg. 2009;35(3):398-402. [DOI]

23. Wang FG, Chen YB, Yang WT, Shi L. Comparison of compensatory sweating and quality of life following thoracic sympathetic block for palmar hyperhidrosis: electrocautery hook versus titanium clip. Chin Med J. 2011;124(21):3495-8.

24. Flores LP. Long-term outcomes associated to video-assisted thoracic sympathotomy for palmar-axillar subtype of the hyperhidrosis. Arq Neuropsiquiatr. 2012;70(6):398-403. [DOI]

25. Purtuloglu T, Deniz S, Atim A, Tekindur S, Gurkok S, Kurt E. A new target of percutaneus sympathic radiofrequency thermocoagulation for treatment of palmar hyperhidrosis: T4. Agri. 2013;25(1):36-40. [DOI]

26. Yanagihara TK, Ibrahimiye A, Harris C, Hirsch J, Gorenstein LA Analysis of clamping versus cutting of T3 sympathetic nerve for severe palmar hyperhidrosis. J Thorac Cardiovasc Surg. 2010;140(5):984-9. [DOI]

27. McCormack AC, Jarral OA, Shipolini AR, McCormack DJ. Does the nerve of Kuntz exist? Interact Cardiovasc Thorac Surg. 2011;13(2):175-8. [DOI]

28. Wen CT, Chu Y, Yeh CJ, Liu CY, Yuan HC, Ko PJ, et al. Feasibility and safety of endoscopic transumbilical thoracic surgical lung biopsy: a survival study in a canine model. J Surg Res. 2013;183(1):47-55. [DOI]

29. Zhu LH, Du Q, Chen L, Yang S, Tu Y, Chen S, et al. One-year follow-up period after transumbilical thoracic sympathectomy for hyperhidrosis: outcomes and consequences. J Thorac Cardiovasc Surg. 2014;147(1):25-8. [DOI]

30. Cruz JM, Fonseca M, Pinto FJ, Oliveira AG, Carvalho LS Cardiopulmonary effects following endoscopic thoracic sympathectomy for primary hyperhidrosis. Eur J Cardiothorac Surg. 2009;36(3):491-6. [DOI]

31. Bygstad E, Terkelsen AJ, Pilegaard HK, Hansen J, Molgaard H, Hjortdal VE. Thoracoscopic sympathectomy increases efferent cardiac vagal activity and baroreceptor sensitivity. Eur J Cardiothorac Surg. 2013;44(3):e193-9. [DOI]
32. Freeman RK, Van Woerkom JM, Vyverberg A, Ascioti AJ. Reoperative endoscopic sympathectomy for persistent or recurrent palmar hyperhidrosis. Ann Thor Surg. 2009;88(2):412-6; discussion 416-7.

33. de Lima AG, Das-Neves-Pereira JC, de Campos JR, Jatene FB Factors affecting long-term satisfaction after thoracic sympathectomy for palmar and plantar hyperhidrosis. Is the sudomotor reflex the only villain? Interact Cardiovasc Thorac Surg. 2011;12(4):554-7. [DOI]

34. Ishy A, de Campos JR, Wolosker N, Kauffman P, Tedde ML, Chiavoni CR, et al. Objective evaluation of patients with palmar hyperhidrosis submitted to two levels of sympathectomy: T3 and T4. Interact Cardiovasc Thorac Surg. 2011;12(4):545-8. [DOI]

35. Atkinson JL, Fode-Thomas NC, Fealey RD, Eisenach JH, Goerss SJ. Endoscopic transthoracic limited sympathotomy for palmarplantar hyperhidrosis: outcomes and complications during a 10-year period. Mayo Clin Proc. 2011;86(8):721-9. [DOI]

36. Hwang JJ, Kim do H, Hong YJ, Lee DY. A comparison between two types of limited sympathetic surgery for palmar hyperhidrosis. Surg Today. 2013;43(4):397-402. [DOI]

37. Yuncu G, Turk F, Ozturk G, Atinkaya C. Comparison of only T3 and T3-T4 sympathectomy for axillary hyperhidrosis regarding treatment effect and compensatory sweating. Interact Cardiovasc Thorac Surg. 2013;17(2):263-7. [DOI]

38. Coveliers H, Meyer M, Gharagozloo F, Wisselink W, Rauwerda J, Margolis M, et al. Robotic selective postganglionic thoracic sympathectomy for the treatment of hyperhidrosis. Ann Thorac Surg. 2013;95(1):269-74. [DOI]

39. Mohebbi HA, Mehrvarz S, Emami S, Manoochehry S, Mohebbi M. Comparison Between R2-R4 and R3-R5 Sympathicotomy for Primary Hyperhidrosis. J Minim Invasive Surg Sci. 2014;3(4):e20543.

40. Miller DL, Bryant AS, Force SD, Miller JI, Jr. Effect of sympathectomy level on the incidence of compensatory hyperhidrosis after sympathectomy for palmar hyperhidrosis. J Thorac Cardiovasc Surg. 2009;138(3):581-5. [DOI]

41. Weksler B, Blaine G, Souza ZB, Gavina R. Transection of more than one sympathetic chain ganglion for hyperhidrosis increases the severity of compensatory hyperhidrosis and decreases patient satisfaction. J Surg Res. 2009;156(1):110-5. [DOI]

42. Gunn TM, Davis DM, Speicher JE, Rossi NP, Parekh KR, Lynch WR, et al. Expanded level of sympathetic chain removal does not increase the incidence or severity of compensatory hyperhidrosis after endoscopic thoracic sympathectomy. J Thorac Cardiovasc Surg. 2014;148(6):2673-6. [DOI]

43. Haam SJ, Park SY, Paik HC, Lee DY. Sympathetic nerve reconstruction for compensatory hyperhidrosis after sympathetic surgery for primary hyperhidrosis. J Korean Med Sci. 2010;25(4):597-601. [DOI]

44. Park HS, Hensman C, Leong J. Thoracic sympathetic nerve reconstruction for compensatory hyperhidrosis: the Melbourne technique. Ann Transl Med. 2014;2(5):45.

45. Inan K, Goksel OS, Ucak A, Temizkan V, Karaca K, Ugur M, et al. Thoracic endoscopic surgery for hyperhidrosis: comparison of different techniques. Thorac Cardiovasc Surg. 2008;56(4):210-3. [DOI]

46. Kang CW, Choi SY, Moon SW, Cho DG, Kwon JB, Sim SB, et al. Short-term and intermediate-term results after unclipping: what happened to primary hyperhidrosis and truncal reflex sweating after unclipping in patients who underwent endoscopic thoracic sympathetic clamping? Surg Laparosc Endosc Percutan Tech. 2008;18(5):469-73. [DOI]

47. Sugimura H, Spratt EH, Compeau CG, Kattail D, Shargall Y. Thoracoscopic sympathetic clipping for hyperhidrosis: long-term results and reversibility. $\mathbf{J}$ Thorac Cardiovasc Surg. 2009;137(6):1370-6; discussion 6-7. [DOI]

48. Thomsen LL, Mikkelsen RT, Derejko M, Schroder HD, Licht PB. Sympathetic block by metal clips may be a reversible operation. Interact Cardiovasc Thorac Surg. 2014;19(6):908-13. [DOI]

49. Miller DL, Force SD. Temporary thoracoscopic sympathetic block for hyperhidrosis. Ann Thorac Surg. 2008;85(4):1211-4; discussion 5-6. [DOI]

50. Walling HW. Clinical differentiation of primary from secondary hyperhidrosis. J Am Acad Dermatol. 2011;64(4):690-5. [DOI] 